GENERAL ARTICLE

\title{
Translating education policy into action in Sri Lanka
}

\author{
Chandra Gunawardena \\ COL-UNESCO Chair in Distance Education, Open University of Sri Lanka, Nawala, Nugegoda
}

\section{INTRODUCTION}

Policy is 'a judgment derived from some system of values and some assessment of situational factors, operating as a general plan for guiding decisions regarding the means of attaining desirable objectives' (Good, 1973). Educational policy may be viewed as a response to broader social, cultural, educational and political change and also as a prescription to change which has to be implemented. The traditional view of policymaking is a technical one in which the researchers are expected to produce a body of knowledge providing the policymakers with information, that could be used to exercise reasoned judgment in finding solutions for policy problems. Education as a policy area, though, constitutes a major responsibility for the state, and policymaking by its nature is essentially a political activity.

Thus, educational policymaking is always a function of the context in which education operates, being shaped by both economic and social imperatives. The significance of these imperatives can vary in different societies and in a particular society at different points of time. In Sri Lanka, the major policies in education targeted democratization of education and elimination of regional and socio-economic inequalities, improvement of the quality of education and from around the sixties focused on meeting the needs of the economy.

The period from 1943 (just prior to independence) to 1972 in Sri Lanka can be broadly considered as one during which nationalist and egalitarian social policies were initiated. There was an evident interest in reforming education to carry forward the impetus of regaining independence, as well as to achieve a democratization of education to reduce existing inequalities related to socio-economic background, urban-rural disparities and gender. As a result, several progressive policies such as free education in 1945, change of the medium of instruction from English to national languages at primary level from 1945, introduced by the Special Committee in Education (1943) and at secondary level from 1950 and at university level in Arts faculties from 1960 and the take-over of denominational schools in 1961 were implemented.

The implementation of these policies had a substantial impact on outcomes as reflected in social indicators such as literacy, and the percentage of those who had no schooling in the population. These policies also led to some reduction of urban-rural disparities in participation in education as well as between girls and boys.

Therefore, this paper focuses briefly on how the context influenced educational policy making in Sri Lanka and the extent to which the translation of policies into action has taken place and on how effectively action has been implemented. It will review policies formulated and action taken during three periods of educational history in Sri Lanka: From 1972 to 1977; from 1977 to 2000 and from 2000 to date, drawing from documented studies and reports.

\section{EDUCATIONAL POLICIES FROM 1972 TO 1977}

The new government which came into power in 1970 gave priority to educational reforms. The major policies which guided educational reforms of 1972 were democratization of education, improving the quality of education by making teaching-learning an active process and focusing on development of dignity of labour. Several programmes of action were initiated under these overarching policies. 
One of the important initiatives taken in 1972 was the restructuring of the school system to provide for a common 9-year primary and secondary education. Thus Mathematics and Science were included as compulsory subjects for all, and Science and Social Studies were offered as integrated subjects. Yet the implementation of these curriculum changes suffered setbacks due to inadequacies in comprehending the constraints prevalent in the country (Gunawardena, 1991).

The 1972 reforms thus gave priority to integrating a vocational component into general education with the introduction of a special curriculum area - Pre-vocational Studies. The subject was allocated $20 \%$ of the time schedule and given a key position in the curriculum. The subject drew on traditional vocational subjects and on the specific occupations of the locality. The subject was seen as a reinforcement of social and economic disparities as the content of the subject was drawn from local occupations. Moreover, these changes in education were not supported by changes in the economic structure and with the change of the government it was eliminated from the curriculum. Pre-vocational Studies thus stands out as an example of a failed venture, stemming from a mix of a lack of proper planning in education and economy and an inability to stand clear of politics (National Education Commission, 2003). The participation in education, especially at secondary level increased during the period from 1970 to 1977 as the following table shows.

Table 1: Enrolment in Schools (1970 \& 1977)

\begin{tabular}{|c|r|r|}
\hline Grades & \multicolumn{1}{|c|}{$\mathbf{1 9 7 0}$} & \multicolumn{1}{|c|}{$\mathbf{1 9 7 7}$} \\
\hline $9-10$ & 310,216 & 367,388 \\
\hline $11-12$ & 45,612 & 87,319 \\
\hline $6-12$ & 942,908 & 991,224 \\
\hline
\end{tabular}

Source: Jayaweera, S., 1989 Educational Policies and Change from the Mid-Twentieth Century to 1977, Occasional Papers in Education, National Institute of Education, Maharagama.

The percentage of the population completing GCE $(\mathrm{O} / \mathrm{L})$ increased from 5.3 in 1973 to 8.8 in 1978, GCE (A/L) from 0.4 to 0.9 and in university education from 0.1 to 0.5. The Seers Report of 1971 on Matching Employment Opportunities and Expectations had a significant impact on official thinking in the seventies. Thus, the Five Year Plan pointed out that 'an educated population becomes a national asset only to the extent that it is able to fit into the productive occupations that the economy is capable of producing'.

This concern led to the introduction at university level, of several job-oriented courses which however failed to achieve the expected objectives as large numbers of graduates following these job-oriented courses found a non-availability of jobs in the areas selected by them (Gunawardena, 1980).

The above policies and reforms had been initiated through the review of the lack of opportunities for general education, when the governments had an obligation and the responsibility to provide opportunities in a context of an increasing demand.

\section{EDUCATIONAL POLICY AND CHANGE: 1977-2000}

De Silva and Gunawardena (1989) in their analysis of educational policy, state that the formulation of educational policy in different (political) regimes had been influenced by several factors, foremost among which were political and social-economic philosophies which affected the manner in which education was viewed by them, the importance accorded to education and selection of priorities in education. During this period also, there was a reiteration of the commitment to educational goals and policies that had hitherto been accepted by policymakers in Sri Lanka.

As in the earlier period, a major focus of educational reform was democratization of education. However, even though the 1978 Constitution had eradication of illiteracy and ensuring universal and equal access to education at all levels as a policy directive (Art.27(2), due to the implementation of structural adjustment programmes from the late 1970s and the social sector expenditure, enrolment and literacy rates stagnated.

In addition, the policymakers had diagnosed the prime need of education to be a qualitative improvement than a quantitative expansion. In 1979, however, contrary to the earlier decision of not supporting private schools, a policy decision was taken to extend assistance to private schools. The establishment of the National Institute of Education in 1986 with broad responsibilities related to postgraduate education, research, initiation and promotion of innovative practices in education, development of professional and managerial competence of personnel was expected to have a positive impact on enhancing the quality of education.

In order to rectify the imbalance between rural and urban schools, the White Paper (1981) presented the proposal on School Clusters. The school cluster had a Core School and the focus was on sharing of resources. The larger 
schools, termed Unitary Schools were to be left out of this scheme and a moratorium on development of these schools was to be fixed with positive discrimination being paid to disadvantaged pupils and deprived schools such as estate and slum schools.

In order to translate the above into action, each district was divided into a number of school zones and the school network in each area was rationalized. Similarly, nearly 600 School Clusters were established even though the sharing of resources envisaged was not achieved. However, even by 1986 the inequalities among urban and rural and privileged and disadvantaged schools and among districts continued, in terms of distribution of school facilities and deployment of teachers. The proposal to separate Unitary Schools which became National Schools subsequently, to make them self-reliant however, stood in stark opposition to the overall policy towards equalization of facilities.

The need to gear education to the economy continued to be a policy objective. The White Paper proposed a new subject of Life Skills, to give the students in Grades 6 to 8 the opportunity to acquire simple skills relevant to a range of vocations and Life Skills replaced PreVocational Studies introduced to the curriculum in 1972. At senior secondary level, Technical subjects were to be taught with some degree of specialization.

The concern for equity had re-surfaced as a consequence of the international norms set by the UN Convention on the Rights of the Child, ratified by Sri Lanka in 1990 and the UN Jomtien Conference on Education for All. In late eighties and early nineties, several ancillary services such as provision of free textbooks from 1980, free midday meals from 1989 to 1994 and free uniform materials from 1993 were introduced.

Similarly, the congruence between education and the economy with the findings of the World Bank study on Education - Employment Linkages (Marga, 1990) highlighted the demands of the private sector for employees equipped with general transferable skills and communication skills in English.

In 1991, the Parliament passed the National Education Commission (NEC) Act No. 19 of 1991 on the recommendation of the Youth Commission (1989). The NEC set out for the first time in the country nine National Goals which subsumed educational goals.

i. National cohesion, National integrity, National unity

ii. A pervasive pattern of social justice iii. A sustainable pattern of living

iv. Generation of work opportunities

v. Human resource development

vi. Partnership in nation building activities to ensure a sense of deep and abiding concern for one another

vii. Learn to adapt to changing situations

viii. Capacity to cope with the complex and the unforeseen.

ix. Securing an honourable place in the international community.

The NEC also identified five competencies that would contribute to the achievement of National Goals. These were

1. Competencies in communication

2. Competencies relating to the environment

3. Competencies relating to religion and ethics

4. Competencies in play and use of leisure: competencies that link up with pleasure, joy, emotions and such human motivations

5. Competencies relating to 'learning to learn'.

The first report of the NEC has made a comprehensive review of available macro data on regional disparities, the school system, district-wise enrolment in education at all levels, growth of educational facilities, school drop-out and repetition, disadvantaged small and estate schools, pupil achievement, teacher education, higher education, and pirivena education to identify issues and problems.

In 1995 the NEC produced a more structured set of reforms presented as 'An Action-oriented Strategy towards a National Education Policy'. The reforms had two major components, (1) extending educational opportunity and (2) quality improvement in education in schools, the teachers' service and educational management. NEC recommended that one or more schools in each educational division and eventually around 600 schools be equipped with all facilities, to be local 'centres of excellence'. The Divisional Schools Project organized in 1995 identified 347 schools and allocated funds for the upgrading of physical infrastructure. 134 of these schools were selected for 'fast track' development in 1998 and in mid-1999 'top priority' was given to the project on the instructions of the President.

In December 1996, a Presidential Task Force on Education was appointed and 12 Technical Committees prepared policy proposals for implementation in general education. The areas considered for reforms spanned a wide range from early childhood development and pre-school education, compulsory education, all levels of general education, promoting teaching of English, 
development of technical and practical skills, special education, value education, counseling and guidance, to strengthening educational management (Presidential Task Force on General Education,1997). Compulsory Education Regulations came into operation from January, 1998 and two types of Committees, School Attendance Committees and School Attendance Monitoring Committees, to monitor attendance at local level were appointed.

The NEC in 1997 had concluded the average level of education quality and learning outcomes as unsatisfactory. Achievement tests indicated shortfalls in mastery of the first language (37\%) and numeracy skills (38\%) at the end of the primary cycle. There were also significant disparities between rural and urban areas.

The Primary Education Reforms were implemented in the Gampaha district in 1998 in Grade 1 and introduced islandwide in 1999. The main objective was to improve the achievement of Essential Learning Competencies. Gradually, curricular reforms focusing on National Goals and Competencies were introduced to other levels of education. At the same time, it had rationalization of schools as one aspect leading to much controversy subsequently, due to the closure of small schools, considered as 'uneconomical units'. This decision was obviously a reversal of the commitment to Education for All. The World Bank (2005) however, claims that rationalization was a well-designed, successful programme.

One important decision arising from the concern of employers about the quality of the products of the education system was to strengthen the teaching of English from primary grades, and to allow certain subjects at junior secondary level and in the Science stream at GCE (A/L) to be offered in the English medium.

\section{EDUCATIONAL POLICIES SINCE 2000}

In 2001 the NEC felt it was opportune to review the progress of the reforms through independent evaluations and public consultations. This was perhaps the first deliberate attempt to commission research and use research findings to make new proposals for reform. Four research studies, nineteen papers and studies undertaken by the National Educational Research and Evaluation Centre (NEREC) were used to review the implemented reforms and formulate proposals.
The findings of the studies are as follows:

1. Compulsory Education Regulations were not implemented effectively and the above-mentioned 240 Committees of the 301 Divisions had ceased to function by 2000 (Perera, 2004).

2. Only around 15 out of the 'fast track' schools had shown significant progress (Kularatne, 2002).

3. NEC coordinated a study of 351 schools (National Education Commission, 2003a) which found that rationalization of schools and closure of small schools had affected the access of children of the poor to education.

4. Gunawardena, et al. (2004) found that all stakeholders responded positively that the primary education reforms were well-designed and implemented systematically and that curricular materials and books were of high quality, though they tended to be uniform and too teacher-directed. Lack of resources, large classes, time consuming record keeping and evaluation tasks affected teacher performance and wide disparities among different types of schools continued and a lack of effective monitoring and supervision was noted.

5. Junior secondary level reforms were found to be conceptually and implementationally weak. Studies (Gunawardena and Lekamge, 2004; Perera et al, 2003) expressed concern about the new subjects in the curriculum, adequacy of human and material resources available for implementation, the teachinglearning process and supervision and monitoring. In addition, deficiencies in formulation of objectives, development of content, teacher preparation to teach integrated subjects, were pointed out in respect of subjects of Environmental Studies, Science and Technology, Practical and Technical Skills, Life Competencies and Social Studies.

6. At senior secondary level, studies by SLAAED (2000), Wijetunga and Rupasinghe (2004), and Karunaratne (2004) revealed that the reforms were well-accepted and implemented, though there were certain constraints such as integration of Botany and Zoology into Biology, the difficulty of completing practical work in Science subjects. The plan to introduce a Technology stream had been abandoned and instead the subject of Technology was put in place. 
7. The English programme was affected by many constraints - lack of teachers, insufficient guidance by In-service Advisers and urban and rural disparities (SLAAED, 2000, Fernando and Mallawa, 2003). However, it has to be noted that in 2009 the President launched 2009 as the year of English and IT. By July 2010, a national cadre of 80 Master Trainers in Spoken English from the 9 provinces had been trained, $60 \%$ of the 22,500 English teachers were trained to teach Spoken/Communicative English, a well-equipped Sri Lanka India Centre for English Language Training was established, tools to test listening and speaking skills at GCE $(\mathrm{O} / \mathrm{L})$ examination (2012)was developed and the first comprehensive Teacher Guide for Spoken English has been produced, used and revised by Master Trainers.

8. A persistent issue affecting the quality of education had been teacher deployment and teacher commitment. Thus, weak teacher deployment and high teacher absenteeism affected the quality of education especially in rural and disadvantaged areas. It was reported that the average leave taken in a school year ranges from 33 days in North-Western province to 42 and 43 in Uva and North-Central Provinces. Among the policy measures recommended were (1) providing incentives to teachers such as extra salary increments, swifter promotions, preferential access to popular schools for the children, construction of teachers' quarters for teachers taking up appointments in disadvantaged areas, (2) allowing teachers to encash unutilized leave and (3) recruiting teachers directly to schools. The first two measures have not been implemented and the third can be done only after revision of existing legislation (World Bank, 2005).

9. School Based Assessment was widely accepted, but difficulties such as its time-consuming nature, doubts regarding reliability of the assessments and implementation in large classes surfaced (Gunawardhane et al., 2002).

Based on the review of above studies, the NEC in 2003 made new recommendations. The eight Goals of Education identified by the NEC in 2003 echoed similar priorities as NEC did in 1972. It added two competencies to the list of 1992: (1) Competencies relating to Personality Development and (2) Competencies relating to Preparation for the world of work obviously being influenced by the continuing concern about the products of the school system.
The policy objectives centred on Access and Equity, Quality and Relevance. Some of the important recommendations are given below:

1. Compulsory education regulations should be extended from 5-14 to 5-16 years.

2. Grade 5 Scholarship Examination should be restructured.

3. Increase family income limit for bursaries.

4. Midday meal should be provided to children in primary schools in disadvantaged communities.

5. Classification of schools should be re-structured making it simpler: Primary - Grade 1-5; Secondary - Grade 1-11/Grade 6 -11; Senior secondary - Grade 1-13/Grade 6-13 and primary schools should be reorganized as feeder schools to secondary schools.

6. At least one school in each administrative division should be identified and developed as a provincial centre of excellence.

7. A limited number of National Schools should be identified on strict criteria.

8. Medium of instruction in primary grades should continue to be Sinhala/Tamil. Bilingualism should be promoted by using English as medium of instruction in selected subjects from Grade 6. Students should be given the option to study in English in $\mathrm{GCE}(\mathrm{O} / \mathrm{L})$ and $(\mathrm{A} / \mathrm{L})$ grades subject to availability of teachers.

9. The Z Score should be used to rank students in each stream for university admission. For admission to courses in medicine, engineering and other sciences, all-island merit quota should be increased from $40 \%$ to $60 \%$ in 2004 and to $80 \%$ in 2006 . Criteria should be revised at each stage after reviewing availability of facilities, especially in rural schools. District Quota should be computed on the basis of the number of candidates sitting for the $\mathrm{A} / \mathrm{L}$ examination and not on the population ratio.

10. Environmental Studies and Social Studies should revert to History, Geography, Civics/Civic Education. History, Geography and Civics should be offered as Social Sciences with three compulsory subjects at the $\mathrm{O} / \mathrm{L}$ examination. At Grades 12-13, the curriculum should not be structured in academic streams Science, Commerce and Arts. 
The donor agencies, especially the World Bank and the Asian Development Bank have been supporting education in the country for more than a decade. As such, policy making in education has been influenced by them as well. Thus, the World Bank (2005) analyzing macro data on enrolment, dropout and repetition, achievement, teacher deployment, preparation and university education, presents its recommendations under the broad areas of;

1. Enhancing equity in access

2. Pursuing excellence in quality

3. Orienting the education system to the world of work

4. Education resource allocation and distribution

5. Improving the quality and efficiency of education service delivery

Among the important recommendations are:

1. Strengthening initiatives especially special education, non-formal education, catch up programmes and use of economic incentives and social mobilization activities to attract and retain vulnerable children in school

2. Developing the quality of basic and senior secondary education

3. Improving understanding at school level of targeted competencies in the primary education curriculum

4. Clarifying and organizing the secondary school curriculum specifying the competencies, skills and expected learning outcomes in each grade and subject

5. Strengthening professional competencies and skills of teachers

6. Strengthening the leadership and management capabilities of principals

7. Expanding the education capital stock and increasing the use of equipment and technology in teaching and learning

8. Improving the quality of textbooks

9. Improving equity and quality through future development of the norm-based, unit cost resource allocation mechanism

10. Increasing private sector investment and participation in education

11. Promoting cost sharing in public university education

12. Developing performance appraisal systems and introducing fiscal incentives for performance

13. Institutional strengthening of central, provincial and zonal education authorities

14. Promoting education research, monitoring and evaluation

It is noted that in respect of the government policies to overcome regional variations in education access, quality and opportunity, the poorer provinces have been paid more attention. Thus, the central government awards lower resources for education in affluent areas such as Western Province (45-50\%) to $100 \%$ in the Northern and Eastern provinces. Similarly, the norm-based unit cost resource allocation formula is built on five criteria: quality input norms, a central equation to allocate resources for recurrent expenditure to schools on a per student basis, fine tuning of the central equation to accommodate economies of scale of large schools and diseconomies of scale of small schools, variations across grade cycles and application of the stock adjustment principle for capital investments. It is claimed that the use of this formula has reduced disparities between schools with similar characteristics from 1:300 in 1996 to $1: 15$ by 2002. Poor schools have enjoyed large inflows of quality inputs.

Following the recommendations of the NEC, the National Institute of Education has revised the secondary school curriculum as a competency based curriculum from 2006. A recent study (SLAAED, 2010) found that the need to develop a competency-based curriculum had been accepted by the curriculum development teams, but formulation of competencies had not been carried out properly. Non-identification of levels of mastery in the achievement of competencies the subjects focus on, appeared to be a major deficiency. The focus on development of higher-order cognitive skills was less in certain subjects.

In 2008, a Committee was appointed to prepare a draft that can be the foundation of a new Education Act to replace the Education Ordinance of 1939. The Committee has finalized a comprehensive report with proposals in seven identified areas which will be placed before the Parliamentary Select Committee shortly.

\section{EDUCATIONAL POLICY AND ACTION IN SRI LANKA}

The above discussion indicates that attempts have been made to translate educational policy into action in Sri Lanka. Especially noteworthy is the period prior to 1972 , when nationalist ideologies were given importance and there was a concerted effort to provide access to education to the majority without making it the privilege of only the elite. This policy was translated into action through several progressive measures described above. During the 1960s except for legislation on the takeover of schools which was effected, other policies formulated failed to be approved or gain acceptance, while others were not followed up seriously. 
The major policy on democratization of education was followed up with zeal by the finalization of curriculum reforms from primary to university level from 1972. Some of the policies, for example, the university admissions policy, which was to be a transitory measure until equal facilities across regions were in place, have continued for decades without attention being given to the root cause for the emergence of such a necessity. On the whole, it appears that, what was implemented with enthusiasm were the curricular reforms in general education over the entire period from 1972 to 2010, though the effectiveness of implementation continues to be questioned.

The 1970s saw a shift of priorities in education policies, with quality and relevance coming to the fore, mainly as a result of educated unemployment, skepticism of the employers, particularly in the private sector and the emergence of Information and Communications Technology. Action to meet the emerging priorities were evident, mainly in the areas of provision of computers, English medium instruction and vocation-oriented subjects in the curriculum, though they continued to be affected by various constraints such as teachercompetency, teacher absenteeism and teacher deployment. Reversals of the university admissions policy and job-orientation of courses occurred as described above. At the same time, some NEC recommendations, for example, on university education, have not been considered for action.

\section{ROLE OF RESEARCH IN POLICY MAKING}

It is pertinent at this point to inquire into the role of research in policy making in education. The traditional view of policy making is to produce a body of knowledge for policy makers, with information that could be used to exercise reasoned judgment in finding solutions for problems. It is assumed that there are alternate means available and the appropriate role for research is to evaluate the effectiveness and efficacy of different means for achieving chosen or intended goals (Good, 1988).

Husen (1988) explains how policy and research settings represent two cultures. Policymakers are concerned only with issues that concern them and these change with the change of political power. They also tend to select evidence from research that support their views. The task of policymaking performance by politicians and civil servants who have their loyalty to a ruling power influences not only what they regard as relevant in research but also their willingness to take them into account.
Reviews of research in education in Sri Lanka indicate the paucity of educational research in general, most of which are dissertations/theses carried out for research degrees. Udagama (1961) in his article on Research in Education reviewed 89 publications, of which 29 were Masters theses and 3 were Ph.D. theses. Some of the research studies had been submitted to overseas universities, while a number of publications were those published in local and international journals.

Gunawardena (1987) selected 50 studies related to the determinants of the effective school from among those available in the libraries of the Ministry of Education, Staff College for Educational Management, Curriculum Development Centre, universities and selected research institutions. He points out that the majority of studies reviewed are dissertations which have mainly utilized the survey method and that the absence of ethnographic studies was a gap in research. Moreover, the majority of the studies were limited in scope and large scale studies undertaken were sparse.

National Education Research and Evaluation Centre of the University of Colombo prepared an annotated bibliography of studies carried out on education in Sri Lanka from 1980 to 2000. These studies were classified under eight broad areas of (1) Education for specific objectives, (2) Educational Psychology, (3) Schools and their activities, (4) Elementary education, (5) Secondary education, (6) Adult education, (7) Higher education and (8) Policy issues in education. In the bibliography, a total of 557 studies have been summarized, 374 of them having been completed prior to 1987 and the rest (183) after 1987. The majority of them were also Masters dissertations.

As pointed out in the above discussion, studies which examined the effectiveness of various policies that were implemented were done mostly after 2000 by the NEC. The World Bank's analysis of macro data related to enrolment, dropout and repetition, education and employment etc., helped to arrive at conclusions about the status of education and to recommend action for the future. It is therefore encouraging to note that at least of late, macro level studies are being commissioned and undertaken as a precursor to policy making in education. However, what is uncertain is whether the findings of such studies are given sufficient attention and whether the necessary follow up action to rectify the deficiencies identified is taken.

Gunawardena (1991) argues that most educational policy making in Sri Lanka has been done intuitively and 
following foreign models mainly of developed societies, at the political level without sufficient consideration of the realities of the situational factors which could have been gained from systematic research activity. However, it is felt that even though all policies may not have stemmed from foreign models, both the lack of sufficiently large scale studies until recently, as well as a lack of serious attention to research to inform policy, appear to make the research-policy nexus in education in Sri Lanka, inadequate.

\section{References}

1. De Silva, W. A. \& Gunawardena, C., 1989. Educational Policies and Change: 1977-1986, Occasional Papers in Education. Maharagama: National Institute of Education.

2. Fernando, R.V \& Mallawa, M., 2003. Study of the Implementation of Activity Based Oral English in Primary Grades I and II: Study Series No. 1. Narahenpita: National Education Commission.

3. Good, C.V., 1973. Dictionary of Education. New York: McGraw.

4. Government of Ceylon, 1959. The Ten Year Plan 1959-1968. Colombo: National Planning Council.

5. Government of Ceylon, 1971. The Five Year Plan 1971-76. Colombo: Ministry of Planning and Employment.

6. Government of Sri Lanka, 1992. The First Report of the National Education Commission. Colombo: Dept. of Government Printing.

7. Gunawardena, G. I. C., 1980. Socio-economic effectiveness of higher education in Sri Lanka : A study of a cohort of Arts graduates. Unpublished Ph.D. Thesis. La Trobe University.

8. Gunawardena, C. et al., 2002. A Study to Investigate the Effectiveness of Implementation of Reforms at Key Stage I of Primary Cycle in Sri Lanka (Unpublished) National Education Research and Evaluation Centre, University of Colombo.

9. Gunawardena, C. \& Lekamge, D., 2004. Evaluation of the Implementation of the Junior Secondary Curriculum in Two Districts: Ratnapura and Kalutara Study Series No. 10, Narahenpita: National Education Commission.
10. Gunawardena, C., Wijetunga, S. \& Perera, L. P., 2004. Evaluation of the Effectiveness of the Implementation of Educational reforms at Secondary School Level (Grades 6 -11) Study Series No. 9. Narahenpita: National Education Commission.

11. Gunawardena, G. B., 1987. Review of Research on Determinants of Effective Schools - Sri Lanka. Maharagama: National Institute of Education.

12. Gunawardena, G. B., 1991. Educational Policy and Research in Sri Lanka: The Link and Future Challenges, Policy Review Series Paper No. 1. Maharagama: National Institute of Education.

13. Gunawardhane, R. et al., 2002. Evaluation of the Implementation of School Based Assessment in Post Primary Classes. University of Colombo: National Education Research and Evaluation Centre.

14. Husen, T., 1988. Educational Research and Policy Making. Oxford: Pergammon Press.

15. International Labour Organization, 1971. Matching Employment Opportunities and Expectations: A Programme of Action for Sri Lanka. Geneva: ILO.

16. Jayaweera, S., 1989. Educational Policies and Change from the Mid-Twentieth Century to 1977, Occasional Papers in Education. Maharagama: National Institute of Education.

17. Karunaratne, S., 2004. Impact Evaluation of 1997 Education Reforms in Teaching Science at the GCE Advanced Level Study Series No. 1., Narahenpita: National Education Commission.

18. Kularatne, N. G., 2002. An Evaluation of the Divisional Schools Development Project and the programme to Revamp Central Schools. Study Series No. 4. Narahenpita: National Education Commission.

19. Marga Institute, 1991. Education-Employment Linkages. Colombo.

20. Ministry of Education (Sri Lanka), 1986. Development of Education 1984-1986: National Report of Sri Lanka. Presented at the International Conference on Education, 40th Session, Geneva.

21. National Education Commission, 1995. An Actionoriented Strategy towards a National Education Policy. 
22. National Education Commission, 2003a. ed. Swarna Jayaweera, Rationalisation of Schools Study Series No. 5, Narahenpita: National Education Commission.

23. National Education Commission, 2003b. Envisioning Education for Human Development: Proposals for a National Policy Framework on General Education in Sri Lanka, Nugegoda: Piyasiri Printing Systems.

24. Perera, S., 2004. Implementation of Compulsory Education Legislation, Study Series No. 2, Narahenpita: National Education Commission.

25. Presidential Task Force on General Education (Sri Lanka), 1997. General Education Reforms, Kuliyapitiya: Sasthrodaya Press.

26. Sessional Paper XXIV of 1943: Report of the Special Committee on Education.

27. Sessional Paper V of 1992: First Report of the National Education Commission.
28. Sri Lanka Association for the Advancement of Education, 2000. Education reforms in Sri Lanka.

29. Sri Lanka Association for the Advancement of Education, 2010. A Study to Examine the Vertical Integration of the Modernized Curriculum Introduced at Secondary Level (Grade 6 -11) since 2007.

30. The World Bank, 2005. Treasures of the Education System in Sri Lanka: Restoring Performance, Expanding Opportunities and Enhancing Prospects. Colombo: World Bank.

31. Udagama, P., 1969. Research in Education, Education in Ceylon: A Centenary Volume III. Colombo: Government Press, pp.1031- 46.

32. Wijetunga, S. \& Rupasinghe, S., 2004. Situational Analysis of General Education Senior Secondary School Curriculum (Grade 10-13) Study Series No. 11. Narahenpita: National Education Commission. 